\title{
Correction to: Dose-responses for mortality from cerebrovascular and heart diseases in atomic bomb survivors: 1950-2003
}

\author{
Helmut Schöllnberger ${ }^{1,2}\left(\right.$ Markus Eidemüller $^{1}\left(\right.$ Ma $^{\circ} \cdot$ Harry M. Cullings $^{3} \cdot$ Cristoforo Simonetto $^{1}\left(\mathbb{D} \cdot\right.$ Frauke Neff $^{4}$. \\ Jan Christian Kaiser ${ }^{1}[$ (])
}

Published online: 24 February 2019

(c) The Author(s) 2019

\section{Correction to: \\ Radiation and Environmental Biophysics (2018) \\ 57(1):17-29. \\ https://doi.org/10.1007/s00411-017-0722-5}

The article Dose-responses for mortality from cerebrovascular and heart diseases in atomic bomb survivors: 1950-2003, written by Helmut Schöllnberger, Markus Eidemüller, Harry M. Cullings, Cristoforo Simonetto, Frauke Neff, Jan Christian Kaiser, was originally published electronically on the publisher's internet portal (currently SpringerLink) on 8 December 2017 without open access. With the author(s)' decision to opt for Open Choice the copyright of the article changed on 24 February 2019 to (c) The Author(s) 2019 and the article is forthwith distributed under the terms of the Creative Commons Attribution 4.0 International License (http://creativecommons.org/licenses/by/4.0/), which permits use, duplication, adaptation, distribution and reproduction in any medium or format, as long as you give appropriate credit to the original author(s) and the source, provide a link to the Creative Commons license and indicate if changes were made.

The original article can be found online at https://doi.org/10.1007/ s00411-017-0722-5.

Helmut Schöllnberger

hschoellnberger@bfs.de

schoellnberger@helmholtz-muenchen.de

1 Helmholtz Zentrum München, Department of Radiation Sciences, Institute of Radiation Protection, Ingolstädter

Landstrasse 1, 85764 Neuherberg, Germany

2 Department of Radiation Protection and the Environment, Federal Office for Radiation Protection, Ingolstädter Landstrasse 1, 85764 Neuherberg, Germany

3 Department of Statistics, Radiation Effects Research Foundation, Hiroshima, Japan

4 Institute of Pathology, Städtisches Klinikum München and Technical University of Munich, Munich, Germany
Open Access This article is distributed under the terms of the Creative Commons Attribution 4.0 International License (http://creativeco mmons.org/licenses/by/4.0/), which permits unrestricted use, distribution, and reproduction in any medium, provided you give appropriate credit to the original author(s) and the source, provide a link to the Creative Commons license, and indicate if changes were made. 